JUCIANE MARIA DE ANDRADE CASTRO

\title{
ASMA EXPERIMENTAL EM LINHAGENS DE CAMUNDONGOS SELECIONADOS PARA MÍNIMA (AIRmin) OU MÁXIMA (AIRmax) RESPOSTA INFLAMATÓRIA AGUDA
}

Tese apresentada ao Programa de Pós-Graduação em Imunologia do Instituto de Ciências Biomédicas da Universidade de São Paulo, para obtenção do Título de Doutor em Ciências.

Área de concentração: Imunologia

Orientador: Prof. Dr. Momtchilo Russo

São Paulo

2010 


\section{RESUMO}

Castro JMA. Asma experimental em camundongos selecionados para mínima (AIRmin) ou Máxima (AIRmax) resposta inflamatória aguda [Tese (Doutorado em Imunologia)]. São Paulo, Brasil: Instituto de Ciências Biomédicas da Universidade de São Paulo; 2010.

Asma é uma doença inflamatória pulmonar crônica usualmente associada com imunidade do tipo 2, eosinofilia pulmonar, hiperreatividade brônquica (airway hyperreactivity - AHR), hiperprodução de muco e altos níveis de IgE. Indivíduos asmáticos podem responder aos alérgenos por duas distintas fases: uma fase imediata (early phase response - EPR) e uma fase tardia (late phase response - LPR). A broncoconstrição a metacolina (methacholine - MCh) pode ter um componente intrínseco ou extrínseco (inflamatório) e é regulada positivamente pela expressão de receptores muscarínicos do tipo 3 (MR3) ou negativamente pelos receptores muscarínicos do tipo 2 (MR2). Apesar dos modelos murinos mimetizarem importantes características da asma humana, como inflamação eosinofílica pulmonar e AHR, a maioria deles falham em reproduzir duas características fundamentais observadas na doença humana como a EPR ou LPR da reação alérgica e o estabelecimento de cronicidade. No presente trabalho utilizamos camundongos AIRmax e AIRmin para avaliar AHR e a inflamação alérgica nestas duas linhagens. Verificamos que camundongos AIRmin respondem com uma broncocostricção intensa (AHR intrínseca) a doses crescentes de metacolina. Esta resposta intensa correlacionou-se com uma menor expressão de receptores muscarínicos do tipo 2 em comparação com os camundongos AIRmax. Em relação a respostas alérgicas induzidas por ovoalbumina (OVA), camundongos AIRmax sensibilizados e desafiados com OVA, ao contrário dos AIRmin, desenvolveram LPR e apresentaram aumento significativo da AHR a doses crescentes de $\mathrm{MCh}$, apresentando valores significativamente mais elevados em relação ao grupo controle quando comparados aos AIRmin. Os AIRmax também montaram uma robusta resposta inflamatória alérgica; estes animais apresentam um denso infiltrado inflamatório com predominância de eosinófilos, uma elevada produção de muco, citocinas (IL-5 e IL-13) no BAL broncho-alveolar lavage - BAL) e anticorpos anafiláticos IgE e IgG1. De forma surpreendente animais AIRmax desenvolvem quadro alérgico pulmonar crônico que cursa com AHR a MCh e uma inflamação pulmonar com infiltrado de eosinófilos com deposição de colágeno no tecido pulmonar além de uma produção elevada de anticorpos anafiláticos. Em conclusão nosso trabalho mostra que animais AIRmin apresentam AHR intrínseca enquanto que animais AIRmax desenvolvem características cardinais da síndrome asmática humana.

Palavras-chave: Asma. OVA. MCh. AHR. M2Rs. EPR. LPR. Inflamação pulmonar crônica. 


\begin{abstract}
Castro JMA. Experimental asthma in mice selected for Minimum (AIRmin) or Maximum (AIRmax) acute inflammatory response. [Ph.D. Thesis (Immunology)]. São Paulo, Brasil: Instituto de Ciências Biomédicas da Universidade de São Paulo; 2010.

Asthma is a chronic inflammatory lung disease usually associated to Type $2 \mathrm{~T}$ helper cells, lung eosinophilia, airway hyper-reactivity (AHR), mucus hyper-secretion and increased titers of $\operatorname{IgE}$. Asthmatic individuals may react to allergens by two distinct phases: an immediate phase (early phase response - EPR) and a late phase (late phase response - LPR). A bronchoconstriction reaction to methacholine $(\mathrm{MCH})$ possesses an intrinsic or extrinsic (inflammatory) components and it is positively regulated by the expression of muscarinic type 3 (MR3) or negatively by muscarinic receptor type 2 (MR2). Although the murine models mimic important features of human asthma such as eosinophilic lung inflammation and AHR, most of them fail to reproduce two key features human asthma, such as eosinophilic lung inflammation and AHR, the majority of animal models fail to reproduce some fundamental features observed in humans as though EPR and LPR of the allergic reaction, and establishment of chronicity. In the present study we use AIRmax AIRmin mice to assess AHR and allergic inflammation in these two strains. We found that AIRmin mice exposed to increasing doses of methacholine presented intense bronchial constriction (intrinsic AHR). This intense reaction was related to a lower expression of muscarinic type 2 receptors compared to AIRmax mice. In relation to allergic responses induced by ovalbumin (OVA), AIRmax mice sensitized and challenged with OVA, unlike AIRmin developed LPR and presented significant augmented AHR to increasing doses of MCh, with values significantly higher in the control group when compared to AIRmin. The AIRmax also developed a robust inflammatory allergic response, presenting a dense inflammatory infiltrate containing predominantly eosinophils, hyper-secretion of mucus, cytokines (IL-5 and IL-13) in the broncho-alveolar lavage (BAL) and anaphylactic antibodies (IgE and IgG1). Surprisingly AIRmax mice develop chronic pulmonary allergic framework that leads to AHR to MCh and lung inflammation with eosinophilic infiltration with collagen deposition in lung tissue and a high production of anaphylactic antibodies. In conclusion, this study demonstrates that AIRmin mice present intrinsic AHR whereas AIRmax mice develop cardinal features of the human asthmatic syndrome.
\end{abstract}

Keywords: Asthma. OVA. MCh. AHR. M2Rs. EPR. LPR. Chronic pulmonary inflammation. 


\section{INTRODUÇÃO}

\subsection{Asma}

As doenças alérgicas afetam aproximadamente 300 milhões de pessoas em todo o mundo e estima-se que 250 mil indivíduos morram de asma anualmente [1]. Durante as últimas três décadas, houve um aumento significativo na prevalência de doenças alérgicas, em particular da asma brônquica, em países desenvolvidos e, principalmente, em países em desenvolvimento, como o Brasil. Segundo dados recentes da Organização Mundial de Saúde (OMS) o Brasil ocupa o sexto lugar entre os países com maior incidência de diagnósticos de asma na população adulta [1-3]. Ainda segundo relatório da OMS estima-se que nos próximos 10 anos haverá um acréscimo de $20 \%$ na ocorrência de asma na população mundial. Mudanças ambientais e, conseqüentemente, as complexas interações genético-ambientais são consideradas responsáveis pelo aumento da prevalência das desordens alérgicas [4].

A asma é uma doença inflamatória que acomete o tecido pulmonar e é caracterizada por uma obstrução do fluxo aéreo devido a alterações funcionais na capacidade de contração da musculatura lisa brônquica. Esta obstrução caracteriza a hiperreatividade brônquica (do inglês, Airway Hyperreactivity - AHR) e ocorre em resposta a uma série de estímulos endógenos ou exógenos [5]. Esse quadro é acompanhado pelo aumento da produção de muco e com o tempo pode levar a mudanças estruturais e funcionais no tecido denominadas de remodelamento pulmonar. Sabe-se que a patogênese da asma brônquica encontra-se associada a componentes genéticos e torna-se mais grave com a exposição a fatores ambientais [5, 6].

Os componentes genéticos que determinam a susceptibilidade à asma podem ser reunidos em quatro grupos principais de genes: o primeiro envolve genes que codificam moléculas associadas com a imunidade inata e imunoregulação (CD14, TLR2, TLR4, TLR6, TLR10, NOD1, NOD2, IL-10, TFG- $\beta$, HLA-DR, HLA-DQ e HLA-DP); o segundo engloba os genes envolvidos com a diferenciação e funções efetoras das células Th2 (GATA2, TBX21, IL-4, IL13, IL-4RA, IL-5, IL-5A e STAT-6); o terceiro contém os genes envolvidos com a biologia e imunidade das células da mucosa (CCL5, CCL11, CCL24, CCL26, DEFB1, SPINK5, FLG, ADAM33, SCGB1A1) e o quarto grupo envolve os genes associados com as funções pulmonares, remodelamento tecidual e gravidade das doenças (TGF, GPRA, ADBR2, TNF, NOS1) [7,8]. Além disso, tem-se um quinto grupo de genes relacionados ao controle da 
contração dos músculos lisos que determinam a susceptibilidade ao desenvolvimento de AHR e, consequentemente a asma [9]. A expressão gênica dessas moléculas colabora para a exacerbação da resposta imune do tipo Th2, responsável pelas reações de hipersensibilidade do tipo I, que caracterizam a asma, e também para os processos de lesão/remodelamento tecidual bem como com o desenvolvimento de AHR que, juntos, causam os sintomas das respostas alérgicas crônicas.

Os fatores ambientais envolvidos na susceptibilidade à asma incluem principalmente exposição ao alérgeno, mudanças de temperatura, baixa umidade, poluição e a exposição a microrganismos patogênicos ou não [10-12].

A classificação da doença é difícil, entretanto, pode ser dividida em duas categorias principais, baseadas na presença ou ausência de um distúrbio imune subjacente: asma extrínseca (ou alérgica) e a asma intrínseca (ou não-alérgica).

A asma intrínseca ocorre em indivíduos sem evidências de alergia e, neste fenótipo da doença vários estímulos podem iniciar a AHR, como por exemplo, aspirina, infecções pulmonares (principalmente as causadas por vírus), frio, stress psicológico, exercício físico e inalação de dióxido de enxofre. A asma intrínseca tem seu início na idade adulta e se caracteriza por uma baixa resposta aos broncodilatadores e necessidade de uso prolongado de corticóides. Os linfócitos $\mathrm{T}$ destes pacientes secretam IL-5, porém, em comparação aos portadores de asma extrínseca alérgica, produzem reduzidas quantidades de IL-4. Além disso, dados da literatura sugerem que a asma intrínseca está relacionada a uma anormalidade nos músculos lisos que permite a estes músculos proliferar mais rapidamente, secretar quimiocinas como eotaxina [13] e IP-10 (CXCL10) [14] as quais são responsáveis pelo influxo de células inflamatórias como eosinófilos e mastócitos, respectivamente, para as vias aéreas [15]. As células musculares podem secretar também proteínas da matriz extracelular responsáveis pelo processo de remodelamento pulmonar que é uma característica da doença asmática. Em conjunto, estas alterações podem geram uma resposta inflamatória direcionada a antígenos desconhecidos e um aumento na AHR que, caracterizam a asma intrínseca [15].

De modo distinto, na asma extrínseca alérgica, que representa a maior parte dos casos de asma, há uma resposta imune direcionada aos alérgenos ambientais [16]. De uma maneira geral, a maior parte dos alérgenos são antígenos de natureza protéica, relativamente pequenos e muito solúveis. Quando em contato com as mucosas, o alérgeno difunde-se através do epitélio e é 
capturado por células dendríticas (do inglês, dendritic cells- DCs) que migram para os linfonodos drenantes onde irão apresentar os antígenos para os linfócitos T. As DCs bem como as demais células apresentadoras de antígeno (do inglês, antigen-presenting cells - APCs) apresentam peptídeos presentes nos alérgenos complexados às moléculas de MHC (do inglês, Major Histocompatibility Complex - MHC) de classe II aos linfócitos T CD4 ${ }^{+}$naive 0 (Th0) específicos, que devido ao microambiente se diferenciam em linfócitos T CD4 ${ }^{+} \mathrm{Th} 2$ (linfócitos Th2). Estes linfócitos Th2 ativados secretam preferencialmente citocinas tipo 2 que são as principais responsáveis pela reação inflamatória característica da asma extrínseca alérgica.

Os Linfócitos Th2 uma vez ativados migram para as zonas ricas em linfócitos B nos linfonodos e induzem a ativação dos linfócitos B alérgeno-específicos que, na presença da citocina IL-4, derivada dos linfócitos Th2 [17, 18], sofrem o processo de troca de isotipo e passam a secretar anticorpos IgE específicos para o alérgeno [19]. Esses anticorpos ligam-se aos receptores de membrana de alta afinidade para a porção Fc da imunoglobulina E (FcєRI), expressos em mastócitos e basófilos, aumentando a sobrevivência e ativação destas células. Outra subclasse de anticorpos produzidos em resposta às citocinas produzidas por linfócitos Th2, a IgG1, também pode ser anafilática [20-22]. Estes eventos caracterizam a fase de sensibilização da resposta alérgica.

Num contato subseqüente com o mesmo alérgeno, ocorrerá ligação cruzada destes à IgE e IgG1 específicos ligados aos receptores na superfície celular de mastócitos e basófilos [23, 24] desencadeando a ativação destas células e a subsequente reação inflamatória característica da asma alérgica $[23,24]$.

A reação inflamatória alérgica produzida em indivíduos sensibilizados após a re-exposição ao alérgeno específico é frequentemente classificada em três fases temporais: a fase imediata (do inglês, Early-Phase Reactions - EPR); a fase tardia (do inglês, Late-Phase Reactions - LPR) e a inflamação alérgica crônica [25], descritas a seguir.

\subsubsection{Resposta asmática imediata e tardia e inflamação crônica}

Herxsheimer, em 1950 [26], observou que a resposta das vias aéreas à inalação de alérgenos em indivíduos sensibilizados apresenta duas fases: a EPR e a LPR. A EPR pode ser 
detectada 10 minutos após a inalação repetida do alérgeno, alcançar o máximo de efeito em 30 minutos e se resolver em 3 horas. A LPR se inicia 2 ou 3 horas após a re-exposição ao alérgeno e pode se estender por mais de $24 \mathrm{~h}$ [26].

Em um indivíduo sensibilizado para um determinado alérgeno, a ligação cruzada destes alérgenos à IgE e IgG1 específicos ligada aos receptores na superfície celular de mastócitos e/ou basófilos é seguida pela ativação de vias secretórias nestas células para liberação de mediadores farmacológicos. Estes mediadores incluem a histamina, o leucotrieno B4 (LTB4), o leucotrieno C4 (LTC4) e a prostaglandina E2 (PGE2) que agem nas células musculares causando intensa resposta broncoconstritora, característica marcante da EPR [27-29].

Estes mediadores lipídicos, juntamente com outras moléculas tais como quimiocinas e citocinas, produzidos na EPR levam à persistência da inflamação e recrutamento de outros tipos celulares caracterizando a LPR.

Na LPR há recrutamento e ativação de eosinófilos, macrófagos e linfócitos Th2 para o tecido pulmonar, sendo que a característica marcante dessa fase é o grande influxo e a ativação de eosinófilos nas vias aéreas [30,31]. Dentre as quimiocinas envolvidas com a inflamação na LPR pode-se citar a CCL-11 (eotaxina), a CCL-5 (RANTES), a CCL-2 (MCP-1), a CCL-3 (MIP-1 $\alpha$ ), a CCL-7 (MCP-3), a CCL-8 (MCP-2), a CCL-13 (MCP-4) e a IL-8 [32]. Além disso, neste processo tem-se a participação das moléculas de adesão e seus receptores (Integrina VLA-1 $\alpha 1 \beta 1$ integrin, very late antigen-1, Integrina VLA-4 - alpha4betal Integrin, very late antigen-4, ICAM-1, VCAM-1) [33-36].

Entre as citocinas envolvidas com a migração de células inflamatórias na LPR destacam-se as citocinas do tipo- 2 derivadas principalmente dos clones de linfócitos Th2 ativados específicos para o alérgeno.

Os linfócitos Th2 ativados, além da citocina IL-4, produzem outras citocinas do tipo-2 tais como IL-3, IL-5, IL-9, IL-13 GM-CSF (do inglês, Granulocyte Macrophage Colony Stimulating Factor- GM-CSF) as quais têm sido descritas como importantes na LPR [37-48]. Estas citocinas em conjunto determinam características marcantes da LPR como: diferenciação e ativação de eosinófilos, secreção de muco, desenvolvimento de AHR a estímulos não alérgicos [19]. Estas moléculas exercem efeitos como mudança de classe dos linfócitos B para a produção de IgE (IL-4 e IL-13), recrutamento de mastócitos (IL-4, IL-9 e IL-13) e maturação de eosinófilos (IL-3, IL-5 e GM-CSF) e basófilos (IL-3 e IL-4) [49]. Na ausência dessas citocinas, não há desenvolvimento de 
resposta alérgica, conforme observado em modelo experimental de indução de asma em camundongos deficientes para IL-4, IL-5, IL-9 e IL-13 [50].

Além dos eventos descritos, durante a fase inicial de exposição ao alérgeno, há participação de citocinas como TSLP (do inglês, Thymic Stromal Lymphopoietin-TSLP), IL-33 e IL-25. A citocina TSLP foi inicialmente descrita como produto secretado por células estromais tímicas [51]. No entanto, células epiteliais e basófilos também secretam TSLP. Citocinas como TNF- $\alpha$, IL-1, IL-4 e IL-13 induzem a produção de TSLP que atua sobre as DCs, linfóticos T, mastócitos, células NK (do inglês, Natural Killer - NK), eosinófilos e linfóticos B. A citocina TSLP direciona a resposta imune para o perfil Th2 também por atuar sobre as DCs [52, 53]. A expressão de TSLP no pulmão de camundongos transgênicos ou a administração de TSLP recombinante induzem intensa inflamação pulmonar, recrutamento de eosinófilos, AHR e produção de muco [54-56].

A IL-33 é uma citocina da família da IL-1 que também contribui para a resposta alérgica por amplificar as respostas do tipo Th2, uma vez que esta citocina induz ativação dos basófilos com consequente produção da citocina IL-4. IL-33 também é responsável por aumentar a sobrevivência de eosinófilos bem como induzir aumento da expressão de moléculas de adesão como ICAM-1 nestas células [57]. A citocinas IL-33 ativa mastócitos a secretar aminas vasoativas, mediadores lipídicos e quimiocinas que contribuem para a reação de anafilaxia [58].

A IL-25 é uma citocina da família da IL-17 produzida por células epiteliais, linfócitos T, eosinófilos, mastócitos e basófilos, também conhecida como IL-17E, que co-estimula a proliferação de células Th2 e a produção de citocinas, principalmente IL-5 [59, 60]. Em modelo murino de asma, a IL-25 é expressa no pulmão dos animais e, quando neutralizada, ocorre redução do recrutamento de eosinófilos e de linfócitos para o espaço aéreo e modulação negativa da resposta imune Th2 [61].

Além disso, a importância de citocinas descritas recentemente também foi comprovada em modelos experimentais, como IL-23 e IL-17 [54, 55, 59, 61-64]. Trabalhos sugerem o envolvimento das citocinas IL17A, IL17F e IL-23 com as respostas alérgicas, tanto na inflamação neutrofílica, quanto no desenvolvimento da resposta Th2 [65-69]. A IL-17 é expressa nas vias aéreas de pacientes asmáticos e correlaciona-se com a gravidade da doença $[65,66]$. Em modelo experimental, tanto a IL-17, quanto a IL-23, produzidas durante a resposta alérgica colaboram para o desenvolvimento da resposta Th2 [64, 67, 68]. Além disso, células como eosinófilos, mastócitos, basófilos também podem produzir estas citocinas e exacerbar ambas EPR e LPR. 
Recentemente foi demonstrado que células NKT (do inglês, natural killer T cell - NKT) que produzem grandes quantidades de IL-4 podem exacerbar a inflamação alérgica e a AHR em modelo murino de asma [70].

Uma vez recrutados e ativados no tecido pulmonar inflamado, os eosinófilos liberam a proteína básica principal (MBP-major basic protein), a proteína catiônica eosinofílica (ECPeosinophilic cationic protein), a peroxidase eosinofílica (EPO-eosinophil peroxidase) e espécies reativas de oxigênio (ROS-reactive oxygen species) responsáveis pelos danos fisiopatológicos no tecido pulmonar incluindo o aumento da resposta das vias aéreas a uma variedade de estímulos, o que pode ser refletido pela AHR à inalação de broncoconstritores como a metacolina [26].

No que se refere à produção de ROS, há várias evidências da participação do metabolismo oxidativo destas células na patogênese da asma. Por exemplo, eosinófilos obtidos de pacientes asmáticos produzem mais ânion superóxido $\left(\mathrm{O}_{2}^{-}\right)$quando comparados a indivíduos saudáveis [71]. Embora o pulmão tenha um desenvolvido sistema antioxidante para proteger a si próprio contra a exposição a oxidantes endógenos ou exógenos nocivos $[72,73]$, a produção excessiva de ROS pode causar inflamação no tecido pulmonar e hiperreatividade das vias aéreas, exacerbando o quadro fisiopatológico da asma [74-76]. Autores sugerem que os efeitos dos ROS no tecido pulmonar são vários, a citar: a injúria das células epiteliais provoca a perda da barreira funcional protetora tornando vários antígenos permeáveis ao tecido ao tecido pulmonar, exacerbando assim a inflamação nas vias aéreas e aumentando a secreção de muco [77] e, indução da produção de prostaglandinas e leucotrienos [78] que podem aumentar a contração das células musculares lisas das vias aéreas. Além disso, pode haver supressão da função dos receptores $\beta$-adrenérgicos [79] com conseqüente aumento da contração da musculatura lisa e exacerbação da AHR a bronconstritores.

Esta intensa resposta inflamatória observada na LPR pode evoluir para uma inflamação alérgica crônica. Esta é o resultado da exposição contínua ou repetitiva ao alérgeno e se caracterizada pela presença de grande número de células inflamatórias da imunidade inata e adaptativa nos tecidos nos locais do desafio com o alérgeno. Esta inflamação persistente é associada com mudanças na matriz extracelular e no número, fenótipo e função das células estruturais.

O processo inflamatório em pacientes com asma crônica envolve mudanças em toda a estrutura das vias aéreas e é tipicamente associada com: hiperplasia/metaplasia das células 
produtoras de muco; hipertrofia epitelial e muscular dos brônquios; aumento na produção de citocinas e quimiocinas pelas células epiteliais; intensa infiltração intraepitelial de eosinófilos, aumento na deposição de componentes da matrix extracelular; proliferação dos fibroblastos, desenvolvimento de miofibroblastos, aumento da vascularidade e aumento na espessura da camada muscular das vias aéreas, com aumento do tamanho, número e função das céulas musculares [80-83]. Estas mudanças são referidas como remodelamento pulmonar e é uma característica da inflamação crônica presente em doenças como asma, dermatite atópica e rinite alérgica $[84,85]$. A consequência mais drástica do processo inflamatório é o declínio irreversível da função pulmonar [86].

\subsubsection{Hiperreativiade brônquica}

O aumento AHR a agentes broncoconstrictores é uma característica marcante da asma. As ações contráteis no músculo liso das vias aéreas, que ocorrem na asma e determinam o desenvolvimento de AHR, são mediadas, na maioria das vezes, pela liberação de histamina, leucotrienos, prostaglandinas e, principalmente acetilcolina ( $\mathrm{ACh}$ ), que se ligam em seus respectivos receptores transmembranares, ativando a cascata de sinalização intracelular que que (1) promovem a liberação de $\mathrm{Ca}^{2+}$ dos estoques intracelulares que permitirá o deslizamento dos filamentos de miosina com os de actina, contraindo o músculo liso das vias aéreas [87] e (2) provocam a abertura de canais de $\mathrm{Ca}^{2+}$ operados por voltagem $\left(\mathrm{Ca}_{\mathrm{v}}\right)$ causando influxo de $\mathrm{Ca}^{2+}$ no citoplasma e, conseqüentemente, a contração do músculo liso [88].

A regulação da contração do músculo liso das vias aéreas é feita por fibras nervosas do sistema parassimpático [89, 90]. A ativação do nervo vago, principal regulador parassimpático das vias aéreas, libera ACh, a qual liga-se aos receptores muscarínicos do tipo M3 (M3R) localizados nas células musculares para causar contração e broncoconstrição ambos em humanos [91] e animais [92]. Por outro lado, a ACh liga-se também aos receptores muscarínicos do tipo 2 (M2R) localizados nos nervos colinérgicos pós-ganglionares e, a ativação destes receptores inibe a liberação de $\mathrm{ACh}$ em um mecanismo de retroalimentação negativa diminuindo a broncoconstrição [90]. 
Os receptores M3 induzem a contração dos músculos lisos das vias aéreas por duas viasdependente e independentes de Cálcio $\left(\mathrm{Ca}^{2+}\right)$. Por meio da subunidade Gq $\alpha$, o receptor M3 ativa a fosfolipase C (PLC), a qual libera 1,4,5-trifosfato de inositol ( $\left.\mathrm{IP}_{3}\right)$ e diacilglicerol (DAG). $\mathrm{IP}_{3}$ induz a liberação de $\mathrm{Ca}^{2+}$ dos estoques no retículo sarcoplasmático. Alternativamente, M3R pode se ligar ao CD38 e, levar a formação de ribose ADP cíclico (cADPR), o qual induz similar liberação de $\mathrm{Ca}^{2+}$ dos estoques intracelulares. $\mathrm{O} \mathrm{Ca}^{2+}$ livre no citoplasma induz a formação da miosina-quinase (MLCK), que fosforila a cadeia leve da miosina (MLC) ativando o processo de contração muscular [93]. A fosforilação da MLC é controlada também por vias que inibem a miosina.fosfatase (MLCP). O DAG derivado da PLC ativa a proteína quinase C (PKC) que, uma vez ativada fosforila a CPI-17 o qual inibe diretamente a ação da MLCP. Além disso, a proteína Rho-quinase, ativada por umas das porções intracelulares do receptor muscarínico M3 também fosforila a CPI-17.

Embora o mecanismo de contração seja desencadeado por ativação do receptor M3, estudos mostram que em doença humana e modelos experimentais de AHR, ocorre diminuição na expressão e/ou na função dos receptores M2, gerando intensa AHR devido a um aumento na liberação de ACh do nervo vago e não devido a uma alteração na expressão e/ou função dos receptores M3 [90]. O receptor inibitório M2 nos nervos parassimpáticos apresentam disfunção em três diferentes modelos animais de asma: infecção aguda com o vírus parainfluenza [94, 95], modelos de sensibilização e desafio com alérgeno [96, 97] e modelos de exposição aguda ao ozônio [98]. Nos modelos de sensibilização e desafio com alérgeno que são caracterizados por intenso infiltrado eosinofílico, a inibição do receptor M2 é feita via MBP liberada dos grânulos dos eosinófilos ativados no local da inflamação. A MBP é uma proteína carregada positivamente que tem a propriedade de se ligar a um grupamento alostérico do receptor M2 inibindo a ligação do agonista e, dessa forma, inibindo qualquer ativação deste receptor [99].

Além da regulação do processo de contração e, consequentemente da AHR, a ACh é um neurotransmissor que exerce um fino controle da inflamação no tecido pulmonar e, portanto é a molécula responsável pela interface entre o sistemas imune e nervoso. Em vários modelos experimentais de asma, autores mostram que a $\mathrm{ACh}$, ao se ligar a outra classe de receptores, os nicotínicos, especialmente o receptor $\alpha 7 \mathrm{nAChR}$ (do inglês, $\alpha 7$ nicotinic acetylcholine receptor) exerce importante efeito anti-inflamatório, reduzindo o influxo total de células inflamatórias e a eosinofilia no lavado broncoalveolar (do inglês, bronchoalveolar lavage, BAL) [100] e reduzindo 
a migração de eosinófilos bem como a produção de leucotrieno C4 (LTC4) e metaloprotease 9 (do inglês, matrix metalloprotease-9 - MMP-9), ambos produzidos por eosinófilos ativados e envolvidos na patogênese da asma [101]. Além disso, sabe-se que agonistas dos receptores nicotínicos da ACh reduzem a proliferação de linfócitos [102] e a expressão de moléculas coestimulatórias como CD28 em linfócitos T [103] e B7 em macrófagos alveolares [104].

Como mencionado, a AHR é uma característica marcante da asma. No entanto, os mecanismos precisos que regulam AHR permanecem obscuros. Os estudos envolvendo modelos animais de AHR têm ajudado a elucidar tais vias associadas ao desenvolvimento de AHR e asma.

A AHR pode ser avaliada quantitativamente empregando diferentes técnicas e tem sido usada em vários estudos que visam identificar genes de susceptibilidade à asma. A AHR brônquica possui um componente intrínseco que tem forte controle genético [105-107]. E, por isso antecede o desenvolvimento de asma, indicando que a AHR não só contribui para a patogenia como é um marcador precoce da doença [108]. Esta AHR que ocorre independente de qualquer processo inflamatório nas vias aéreas é denominada AHR intrínseca ou não inflamatória e caracteriza a asma intrínseca. Além disso, os fatores ambientais, como a exposição à alérgenos ou infecção podem igualmente influenciar a AHR e, neste caso gerar a AHR inflamatória observada em indivíduos com asma extrínseca alérgica [109].

Em relação ao componente inflamatório da AHR, existem dois subtipos de AHR, um variável e induzível e outro persistente. A AHR variável reflete o processo inflamatório desencadeado pela exposição ao alérgeno. Roger Altounyan foi o primeiro pesquisador a observar relação de desenvolvimento de AHR e inflamação [110]. A partir desse estudo várias constatações foram feitas demonstrando a relação entre células inflamatórias, particularmente eosinófilos, mastócitos e basófilos bem como o aumento da produção de citocinas tais como IL-4, IL-5 e IL-13 e o desenvolvimento de AHR [111-115].

A AHR persistente é observada em pacientes com asma crônica e correlaciona-se a mudanças estruturais e/ou fisiológicas decorrentes do remodelamento pulmonar. Esse componente da AHR é provocado pelas modificações teciduais que incluem deposição de colágeno (fibrose) hipertrofia e/ou hiperplasia das células musculares das vias aéreas e mudanças na composição da matriz extracelular que, em conjunto provocam aumento da espessura da perede das vias aéreas [116]. Além disso, o desenvolvimento da AHR em camundongos tem sido associado à pelo menos dois mecanismos distintos: um dependente da citocina IL-4, anticorpos 
IgE e mastócitos [117] e outro dependente da citocina IL-5 e eosinófilos [118-120]. De acordo com os dados da literatura, estes dois mecanismos possuem ação independente no desenvolvimento de AHR [121].

Em modelos murinos, a AHR intrínseca e a AHR inflamatória podem ser avaliadas antes e após a indução experimental de inflamação alérgica das vias aéreas, respectivamente. E, estes modelos forneceram um conjunto de dados que permitiram avançar os conhecimentos sobre os mecanismos que operam no controle da AHR. Estes estudos mostram que AHR não- inflamatória é intrínseca e controla geneticamente em linhagens puras [106, 122, 123], e que AHR inflamatória nestas mesmas linhagens também tem um componente hereditário. Neste cenário, em um trabalho recente, Camateros et al. (2009) [9] identificaram genes candidatos ao fenótipo de AHR em oito novas regiões cromossômicas, adicionadas as oito regiões identificadas anteriormente por este e outros grupos. Estes genes estão todos expressos nos pulmões e são eles: Ddr2 (do inglês, Discoidin domain receptor family member 2 - Ddr2) envolvido com a síntese de colágeno [124]; o Hc (do inglês, Hemolytic complement - Hc) envolvido na modulação da AHR [125] , Fbnl (do inglês, Fibrilin 1 - Fbn1) envolvido na produção da matriz extracelular [126]; Utrn (do inglês, Utrophin - Utrn ) envolvido na expressão dos receptores de ACh e na sinapse neuromuscular [127]; Enpp2 (do inglês, Ectonucleotide pyrophosphatase/phosphodiesterase 2 Enpp2) envolvido no controle da função pulmonar [128] e o Tsc2 (do inglês, Tuberous sclerosis - Tsc2) que regula o crescimento e a diferenciação das células musculares lisas [129].

Dados da literatura sugerem que os genes que controlam a AHR intrínseca, envolvidos primordialmente no controle da contração da musculatura lisa brônquica [9], podem positiva ou negativamente controlar a AHR inflamatória. Um exemplo clássico do controle negativo está nos camundongos das linhagens C57BL/6 e C3H/HeJ, que apesar de desenvolverem intensa resposta inflamatória, permanecem hiporesponsivos a broncoconstrição induzida por metacolina [130, 131]. O controle positivo da AHR inflamatória foi demonstrado por Wills-Karp (1997) que revelou camundongos A/J, que possuem AHR intrínseca, quando sensibilizados e desafiados com alérgeno desenvolvem uma AHR mais intensa. Esta autora constatou que genes adicionais, como os genes que influenciam a diferenciação de linfócitos Th2, contribuem para AHR inflamatória [132].

Além disso, sabe-se que a AHR inflamatória pode ser controlada por mecanismos genéticos independentes da AHR intrínseca e sim envolvidos com o processo inflamatório propriamente 
dito. Vários trabalhos mostram que a AHR inflamatória está correlacionada com distintos marcadores de inflamação das vias aéreas na asma. Estes incluem eosinofilia [111], presença de mastócitos [111] e células epiteliais no BAL [133] bem como a hiper-produção de muco e deposição de colágeno nas vias aéreas [113]. Utilizando camundongos knockout (KO) e transgênicos foi confirmada a participação dos genes para as citocinas como IL-4, IL-5, IL-6, IL8, IL-11 e IL-13 na fisiopatologia da asma, incluindo a AHR [134].

\subsection{Modelos de asma experimental}

Assim como a maioria das doenças humanas, estudos com animais de laboratório produzidos ao longo das décadas permitiram avançar no conhecimento dos mecanismos operacionais envolvidos na imunopatologia da asma.

Os primeiros modelos animais de asma foram desenvolvidos em uma variedade de espécies [135] e focaram no fenômeno de AHR, definida como excessiva broncoconstrição em resposta a um desafio com agonistas do músculo liso como metacolina. Estes agonistas possuem objetivo de mimetizar as ações dos mediadores liberados pelas células inflamatórias durante um ataque de asma alérgica [136]. Apartir de 1980, com o avanço na elucidação da participação da resposta imune na patologia da asma, os modelos experimentais têm focado em ambas AHR e resposta imune na asma alérgica. Assim, nos últimos quinze anos, modelos animais, especialmente modelos murinos, de asma experimental têm sido usados para investigar os mecanismos imuno-patológicos que conduzem a desenvolvimento da doença.

Várias linhagens de camundongos podem ser utilizadas juntamente com os mais diversos alérgenos para a sensibilização dos animais, como por exemplo, antígenos ambientais, normalmente envolvidos nas patologias humanas [137-140]. Esses antígenos podem ser extratos de ácaros domésticos, extratos de determinadas espécies de baratas, grãos de pólen e antígenos específicos desses alérgenos expressos na forma de proteína recombinante. A proteína ovoalbumina (OVA) é um alergeno alimentar que apesar de não representar um alérgeno pulmonar relevante na população humana, é um dos antígenos mais empregados como alérgeno nos modelos experimentais murinos de alergia em função da facilidade para sua obtenção e capacidade de induzir resposta imune mediante imunização com adjuvante. Os modelos murinos 
de alergia empregando a proteína OVA foram padronizados na década de 90 e são empregados atualmente para as mais diversas finalidades [141-147]. Nestes modelos, atualmente adaptados, realiza-se a sensibilização dos animais com a proteína, em presença de adjuvante como o gel de hidróxido de alumínio (Alum). Neste tipo de protocolo a resposta alérgica é claramente mediada por linfócitos Th2 juntamente com um aumento significativo do número total de células no BAL, predominantemente eosinófilos (60-80\%), além disso, ocorre produção de citocinas como IL-4, IL-5, IL-9 e IL-13 e de anticorpos IgE e IgG1 OVA-específicos. Além disso, os animais AHR a concentrações crescentes de broncoconstritores como a metacolina (MCh). A importância de citocinas descritas recentemente como a IL-25, IL-33, TSLP, IL-23 e IL-17 [54, 55, 59, 61-64].

Estes modelos fornecem uma visão sobre os mecanismos imunológicos da inflamação alérgica aguda e ajudam a elucidar células e moléculas de ambos, sistema imune inato e adaptativo, que desempenham papéis fundamentais na regulação do processo inflamatório local. Além disso, os modelos experimentais de asma fornecem valiosa ferramenta para investigar a interação neuro-imunológica subjacente ao desenvolvimento de alergia [148-150].

Apesar dos modelos murinos mimetizarem importantes características da asma humana, como inflamação pulmonar e AHR, a maioria deles falha em reproduzir três características fundamentais observadas na doença humana como a EPR e a LPR bem como a cronicidade da resposta alérgica. Zosky et al. (2008) demonstraram que camundongos BALB/c sensibilizados e desafiados com OVA desenvolveram AHR a MCh mas não desenvolveram LPR apesar de intenso infiltrado inflamatório. Estes autores mostram as limitações do modelo murino como uma ferramenta para se estudar a disfunção pulmonar associada com a asma [151].

Um dos mais recentes focos dos estudos envolvendo asma alérgica é a questão da cronicidade da exposição ao alérgeno. O processo de sensibilização e desafio descritos acima, que desencadeiam a inflamação das vias aéreas e a AHR à MCh é um processo agudo o que não reflete a doença humana, uma vez que asma em humanos é tipicamente uma doença crônica que possui características tais como remodelamento pulmonar [152].

Assim, na tentativa de elucidar as alterações nas vias aéreas decorrentes da cronicidade da doença, diferentes grupos de pesquisadores têm estudado o efeito da exposição crônica ao alérgeno em camundongos. No entanto, na maioria dos protocolos testados, a exposição crônica a ovoalbumina em camundongos BALB/c previamente sensibilizados conduzem a um fenômeno conhecido como "tolerância inalatória local”, caracterizado pela diminuição da inflamação 
pulmonar e hiperreatividade brônquica $[153,154]$, porém os animais apresentam altos níveis de IgE, daí o termo local [155]. Neste contexto, existem poucos dados na literatura que mostram presença de infiltrado inflamatório e AHR em camundongos desafiados cronicamente com o alérgeno; Goplen et al. (2009) mostraram que a exposição a múltiplos antígenos produz inflamação na ausência de adjuvante e pode quebrar a tolerância e produzir um fenótipo crônico [156]. Corroborando estes dados, Wegmann et al. (2005) demonstraram que três sensibilizações intraperitoneais com OVA adsorvida a Alum seguida por doze semanas de desafio com OVA com uma freqüência de dois desafios por semana, produzem inflamação alérgica crônica e AHR persistente [157]. No entanto, o modelo de asma crônica possui grande limitação devido ao escasso número de dados na literatura e a dificuldade de reprodução dos achados.

Além do exposto, a complexa fisiopatologia da asma torna difícil a elucidação das suas reais causas: uma resposta inflamatória ou anormalidade intrínseca dos músculos lisos das vias aéreas ou ambos simultaneamente [158], ou seja, a relação entre AHR e inflamação permanece ainda como uma temática a ser explorada pelos pesquisadores.

Em conjunto estes achados apontam que asma é uma síndrome complexa que pode ser mediada por diferentes mecanismos genéticos e imunológicos. Portanto, o desenvolvimento de modelos experimentais utilizando distintas linhagens de camundongos é de interesse para se entender e dissecar os diferentes mecanismos imunológicos envolvidos nestes processos patológicos.

\subsection{Linhagens de camundongos selecionados para máxima (AIRmax) ou mínima (AIRmin) resposta inflamatória aguda}

As linhagens de alta (AIRmax) ou baixa (AIRmin) reatividade inflamatória aguda foram obtidas por Seleção Genética Bidirecional a partir de uma população geneticamente heterogênea (F0) constituída por cruzamentos equilibrados entre oito linhagens isogênicas (A/J, BALB/cJ, C57BL/6J, CBA/J, DBA/2J, P/J, SJL/J e SWR/J) (Figura 1). 


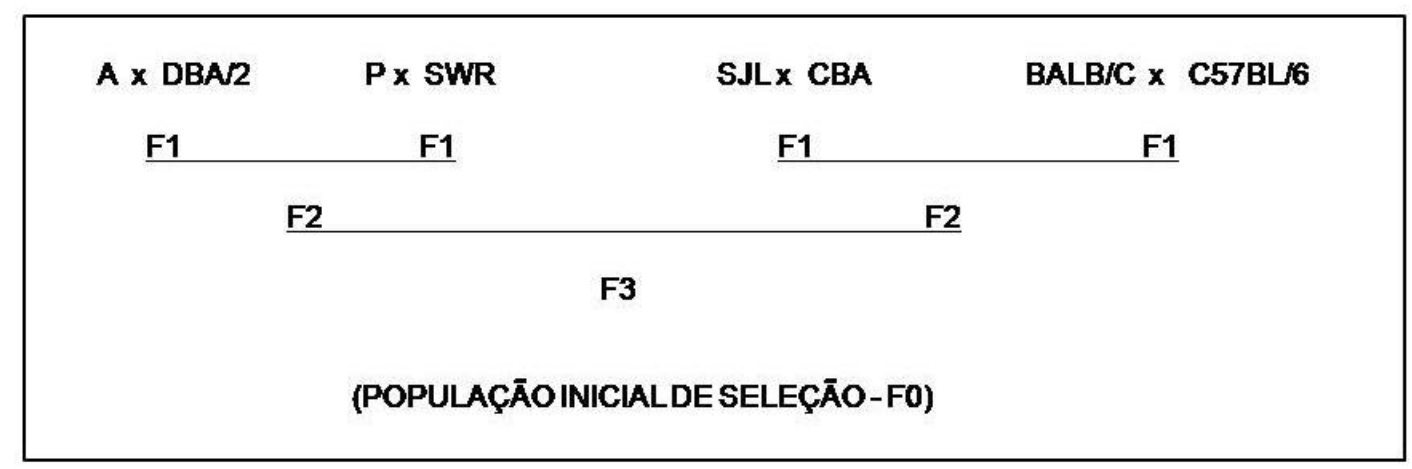

Figura 1. Obtenção da população F0.

A partir da população F0, foram selecionados aqueles animais que apresentaram alta ou baixa reatividade inflamatória aguda (AIR), segundo o número de leucócitos infiltrados e o teor de proteínas extravasadas em resposta à injeção subcutânea de Biogel, agente quimicamente inerte e não imunogênico [159].

Os acasalamentos dos animais escolhidos nos extremos de resposta máxima (AIRmax) ou mínima (AIRmin) foram repetidos em gerações consecutivas, até ser atingido o limite máximo de separação entre as duas linhagens, ao redor da vigésima geração de acasalamentos seletivos. Observou-se a conservação dos fenótipos extremos nas gerações posteriores, indicando que os genes relacionados aos caracteres selecionadores fixaram-se em homozigose em cada linhagem, mantendo-se, entretanto, um fundo genético heterogêneo [160].

A diferença entre as duas linhagens no número médio de leucócitos migrantes ao sítio de injeção do Biogel é de aproximadamente 20 vezes a favor da AIRmax, sendo os neutrófilos as células predominantes no exsudato. Esta diferença é um fenômeno geral que afeta todos os tecidos vascularizados em resposta a vários agentes flogísticos, tais como carragenina, zimosan e bactérias vivas ou inativas [160]. Este maior número de neutrófilos encontrado no exsudato dos camundongos AIRmax é decorrente de três fatores: maior capacidade da medula óssea em produzir neutrófilos maduros; maior produção de fatores quimiotáticos pelas células residentes ou infiltrantes após tratamento com Biogel e maior resistência à apoptose das células do exsudato [161].

A resposta imune específica dos camundongos AIRmax e AIRmin parece não ter sido afetada pelo processo seletivo, uma vez que estas linhagens produzem níveis equivalentes de anticorpos contra antígenos naturais complexos (eritrócitos, proteínas heterólogas e bactérias 
inativadas). Igualmente, as reações de hipersensibilidade tardia a eritrócitos ou Salmonella typhimurium foram idênticas nas duas linhagens. Por outro lado, camundongos AIRmax são significativamente mais resistentes a infecções por patógenos intracelulares do que os AIRmin. Os AIRmax diferenciam-se dos AIRmin na ordem de 1000, 100 e 50 vezes as DLs50 para Salmonellat typhimurium, Listeria monocytogenes e Escherichia coli, respectivamente. Esta maior resistência dos AIRmax está diretamente relacionada com a sua habilidade em controlar o crescimento bacteriano no baço, à resposta inflamatória local e à produção de citocinas [162] .

Estes animais foram também analisados quanto a sua capacidade em desenvolver tumores quimicamente induzidos ou transplantados. Camundongos AIRmax apresentaram maior resistência ao desenvolvimento de tumores cutâneos do que os AIRmin, tanto no número de papilomas (multiplicidade) como na porcentagem de animais acometidos (incidência) [163].

No presente estudo, verificamos se estes camundongos, selecionados por mecanismos imunológicos para desenvolverem uma resposta máxima (AIRmax) ou mínima (AIRmin) a estímulos inflamatórios agudos [160] também são capazes de montar uma resposta imune adaptativa do tipo Th2, máxima e mínima e, se devido às peculiaridades na montagem da resposta imune, estes camundongos permitem reproduzir características da asma até então parcialmente mimetizadas nos modelos experimentais tradicionalmente utilizados para se estudar a asma.

Como animais AIRmax possuem um componente inflamatório inato (recrutamento de neutrófilos) extremamente polarizado devido a hiper-atividade da medula óssea, resistência à apoptose das células inflamatórias e maior produção de quimiocinas é possível que este mesmo fenômeno se reflita também em relação à inflamação alérgica eosinofílica mediada por células Th2, uma vez que estas células da imunidade inata (neutrófilos e eosinófilos) possuem o mesmo precursor, o mieloblasto. Desta forma as reações mediadas por eosinófilos foram estudadas em maior detalhe. Neste sentido foi dada ênfase especial à LPR e o estabelecimento de inflamação alérgica crônica com remodelamento pulmonar.

Além disso, como a AHR a bronconstritores como a metacolina possui um componente intrínseco, que ocorre independente de qualquer processo inflamatório nas vias aéreas e tem forte controle genético e também um componente influenciado por fatores ambientais, como a exposição à alérgenos ou pela resposta inflamatória, investigamos nestas duas linhagens de camundongos o desenvolvimento de AHR não inflamatória (intrínseca) e AHR induzida por 
alérgeno. E, por fim, como a ACh é um neurotransmissor responsável que regula o processo de contração dos músculos lisos e também exerce um fino controle na inflamação no tecido pulmonar sendo, portanto a molécula responsável pela interface entre o sistemas imune e nervoso, investigamos a relação do desenvolvimento de AHR nos camundongos que respondem com mínima resposta inflamatória (AIRmin). 


\section{CONCLUSÕES}

Nossos resultados mostram que camundongos AIRmin não tratados apresentaram uma AHR intrínseca a crescentes doses de MCh. E, esta linhagem apresentou baixos níveis de ambos mRNA e proteína do receptor M2 e foi irresponsiva a galamina. Além disso, nenhuma alteração na função e/ou expressão foi notada para o receptor M3. Assim, demonstramos que a AHR intrínseca em camundongos AIRmin foi nitidamente dependente da expressão e/ou função dos receptores $\mathrm{M} 2$.

A investigação da função pulmonar de camundongos tratados com OVA acrescida de Alum a fim de se estudar asma extrínseca demonstrou que camundongos AIRmax tratados com OVA, ao contrário dos AIRmin, desenvolvem também uma nítida LPR. E, os camundongos AIRmax desenvolveram AHR a doses crescentes de MCh e camundongos AIRmin foram mais sensíveis a MCh em relação aos AIRmax uma vez que estes animais responderamm com grande aumento de AHR já na dose baixa enquanto que os AIRmax tratados com OVA apresentaram aumento significativo da AHR em relação ao controle apenas nas doses altas. Os camundongos AIRmax tratados com OVA foram irresponsivos a galamina. Assim, reproduzimos experimentalmente dois fenótipos de AHR a MCh, a AHR intrínseca e a AHR inflamatória e mostramos que em ambos os fenótipos de AHR, a broncoconstrição foi induzida por uma disfunção nos receptores M2.

A análise da resposta inflamatória desencadeada pela sensibilização e desafio com OVA demonstrou que os camundongos AIRmax tratados com OVA foram capazes de montar uma robusta resposta inflamatória característica de asma alérgica (asma extrínseca); estes animais apresentaram um denso infiltrado inflamatório com predominância de eosinófilos, uma elevada produção de muco, $\mathrm{H}_{2} \mathrm{O}_{2}$, citocinas Th2 (IL-5 e IL-13) no BAL e anticorpos anafiláticos IgE e IgG1 no soro. Por outro lado, os camundongos AIRmin tratados com OVA, quando comparados aos AIRmax, apresentaram uma modesta inflamação pulmonar com baixos níveis dos parâmetros citados anteriormente.

Semelhante ao observado após exposição aguda a OVA, após a exposição crônica a OVA os camundongos AIRmax desenvolveram intensa AHR a MCh e uma robusta inflamação pulmonar crônica caracterizada por grande influxo de eosinófilos e produção de anticorpos anafiláticos, IgE e IgG1 envolvidos com a patogênese da asma. Em contraste, nos camundongos 
AIRmin a exposição crônica a OVA diminui drasticamente o número de células inflamatórias. Além disso, a deposição de colágeno no tecido pulmonar dos camundongos AIRmax com exposição crônica a OVA mostrou um aumento significativo (4X) quando comparados aos animais do grupo agudo . Porém, nos animais AIRmin, este aumento foi de $2 \mathrm{X}$.

Estes nossos resultados representam uma nova ferramenta de estudo da cronicidade da resposta alérgica observadas na asma humana. 


\section{REFERÊNCIAS*}

[1] Sembajwe G, Cifuentes M, Tak SW, Kriebel D, Gore R, Punnett L. National income, selfreported wheezing and asthma diagnosis from the World Health Survey. Eur Respir J. Feb;35(2):279-86.

[2] Bousquet J, Clark TJ, Hurd S, Khaltaev N, Lenfant C, O'Byrne P, et al. GINA guidelines on asthma and beyond. Allergy. 2007 Feb;62(2):102-12.

[3] Farrar JR. The global burden of asthma and current approaches to its managment. Business Briefings:Eur Pharmacother. 2005:1-6.

[4] Marks GB. Environmental factors and gene-environment interactions in the aetiology of asthma. Clin Exp Pharmacol Physiol. 2006 Mar;33(3):285-9.

[5] Holgate ST. Pathogenesis of asthma. Clin Exp Allergy. 2008 Jun;38(6):872-97.

[6] Holgate ST, Davies DE. Rethinking the pathogenesis of asthma. Immunity. 2009 Sep $18 ; 31(3): 362-7$.

[7] Steinke JW, Borish L, Rosenwasser LJ. 5. Genetics of hypersensitivity. J Allergy Clin Immunol. 2003 Feb;111(2 Suppl):S495-501.

[8] Vercelli D. Discovering susceptibility genes for asthma and allergy. Nature reviews. 2008 Mar;8(3):169-82.

[9] Camateros P, Marino R, Fortin A, Martin JG, Skamene E, Sladek R, et al. Identification of novel chromosomal regions associated with airway hyperresponsiveness in recombinant congenic strains of mice. Mamm Genome. Feb;21(1-2):28-38.

[10] Yazdanbakhsh M, Kremsner PG, van Ree R. Allergy, parasites, and the hygiene hypothesis. Science. 2002 Apr 19;296(5567):490-4.

[11] Arshad SH, Kurukulaaratchy RJ, Fenn M, Waterhouse L, Matthews S. Rhinitis in 10year-old children and early life risk factors for its development. Acta Paediatr. 2002;91(12):13348.

[12] Hansbro PM, Beagley KW, Horvat JC, Gibson PG. Role of atypical bacterial infection of the lung in predisposition/protection of asthma. Pharmacol Ther. 2004 Mar;101(3):193-210.

\footnotetext{
* De acordo com:

International Committee of Medical Journal Editors. Uniform requeriments for manuscripts submitted to Biomedical Journal: sample references. Available from: http://www.icmje.org [2007 May 22].
} 
[13] Chan V, Burgess JK, Ratoff JC, O'Connor B J, Greenough A, Lee TH, et al. Extracellular matrix regulates enhanced eotaxin expression in asthmatic airway smooth muscle cells. Am $\mathbf{J}$ Respir Crit Care Med. 2006 Aug 15;174(4):379-85.

[14] Brightling CE, Ammit AJ, Kaur D, Black JL, Wardlaw AJ, Hughes JM, et al. The CXCL10/CXCR3 axis mediates human lung mast cell migration to asthmatic airway smooth muscle. Am J Respir Crit Care Med. 2005 May 15;171(10):1103-8.

[15] Black JL, Roth M. Intrinsic asthma: is it intrinsic to the smooth muscle? Clin Exp Allergy. 2009 Jul;39(7):962-5.

[16] Humbert M, Menz G, Ying S, Corrigan CJ, Robinson DS, Durham SR, et al. The immunopathology of extrinsic (atopic) and intrinsic (non-atopic) asthma: more similarities than differences. Immunol Today. 1999 Nov;20(11):528-33.

[17] Coffman RL, Carty J. A T cell activity that enhances polyclonal IgE production and its inhibition by interferon-gamma. J Immunol. 1986 Feb 1;136(3):949-54.

[18] Minty A, Chalon P, Derocq JM, Dumont X, Guillemot JC, Kaghad M, et al. Interleukin13 is a new human lymphokine regulating inflammatory and immune responses. Nature. 1993 Mar 18;362(6417):248-50.

[19] Larche M, Robinson DS, Kay AB. The role of T lymphocytes in the pathogenesis of asthma. J Allergy Clin Immunol. 2003 Mar;111(3):450-63; quiz 64.

[20] Oshiba A, Hamelmann E, Takeda K, Bradley KL, Loader JE, Larsen GL, et al. Passive transfer of immediate hypersensitivity and airway hyperresponsiveness by allergen-specific immunoglobulin (Ig) E and IgG1 in mice. J Clin Invest. 1996 Mar 15;97(6):1398-408.

[21] Faquim-Mauro EL, Jacysyn JF, Macedo MS. Anaphylactic and non-anaphylactic murine IgG1 differ in their ability to bind to mast cells: relevance of proper glycosylation of the molecule. Immunobiology. 2003;207(3):169-77.

[22] Macedo-Soares MF, Itami DM, Lima C, Perini A, Faquim-Mauro EL, Martins MA, et al. Lung eosinophilic inflammation and airway hyperreactivity are enhanced by murine anaphylactic, but not nonanaphylactic, IgG1 antibodies. J Allergy Clin Immunol. 2004 Jul;114(1):97-104.

[23] Gould HJ, Sutton BJ. IgE in allergy and asthma today. Nature reviews. 2008 Mar;8(3):205-17.

[24] Bischoff SC. Role of mast cells in allergic and non-allergic immune responses: comparison of human and murine data. Nature reviews. 2007 Feb;7(2):93-104. 
[25] Galli SJ, Tsai M, Piliponsky AM. The development of allergic inflammation. Nature. 2008 Jul 24;454(7203):445-54.

[26] Herxheimer H. The late bronchial reaction in induced asthma. Int Arch Allergy Appl Immunol. 1952;3(4):323-8.

[27] Santing RE, Olymulder CG, Zaagsma J, Meurs H. Relationships among allergen-induced early and late phase airway obstructions, bronchial hyperreactivity, and inflammation in conscious, unrestrained guinea pigs. J Allergy Clin Immunol. 1994 Jun;93(6):1021-30.

[28] Santing RE, Schraa EO, Wachters A, Olymulder CG, Zaagsma J, Meurs H. Role of histamine in allergen-induced asthmatic reactions, bronchial hyperreactivity and inflammation in unrestrained guinea pigs. Eur J Pharmacol. 1994 Mar 11;254(1-2):49-57.

[29] Schuiling M, Zuidhof AB, Meurs H, Zaagsma J. Role of tachykinin NK2-receptor activation in the allergen-induced late asthmatic reaction, airway hyperreactivity and airway inflammatory cell influx in conscious, unrestrained guinea-pigs. $\mathrm{Br} \mathrm{J}$ Pharmacol. 1999 Jun;127(4):1030-8.

[30] Aalbers R, Kauffman HF, Vrugt B, Smith M, Koeter GH, Timens W, et al. Bronchial lavage and bronchoalveolar lavage in allergen-induced single early and dual asthmatic responders. Am Rev Respir Dis. 1993 Jan;147(1):76-81.

[31] Metzger WJ, Richerson HB, Worden K, Monick M, Hunninghake GW. Bronchoalveolar lavage of allergic asthmatic patients following allergen bronchoprovocation. Chest. 1986 Apr;89(4):477-83.

[32] Gonzalo JA, Lloyd CM, Kremer L, Finger E, Martinez AC, Siegelman MH, et al. Eosinophil recruitment to the lung in a murine model of allergic inflammation. The role of $\mathrm{T}$ cells, chemokines, and adhesion receptors. J Clin Invest. 1996 Nov 15;98(10):2332-45.

[33] Anwar AR, Walsh GM, Cromwell O, Kay AB, Wardlaw AJ. Adhesion to fibronectin primes eosinophils via alpha 4 beta 1 (VLA-4). Immunology. 1994 Jun;82(2):222-8.

[34] Walsh GM, Symon FA, Lazarovils AL, Wardlaw AJ. Integrin alpha 4 beta 7 mediates human eosinophil interaction with MAdCAM-1, VCAM-1 and fibronectin. Immunology. 1996 Sep;89(1):112-9.

[35] Wardlaw AJ, Moqbel R, Cromwell O, Kay AB. Platelet-activating factor. A potent chemotactic and chemokinetic factor for human eosinophils. J Clin Invest. 1986 Dec;78(6):17016.

[36] Walsh GM, Hartnell A, Wardlaw AJ, Kurihara K, Sanderson CJ, Kay AB. IL-5 enhances the in vitro adhesion of human eosinophils, but not neutrophils, in a leucocyte integrin (CD11/18)-dependent manner. Immunology. 1990 Oct;71(2):258-65. 
[37] Sanderson CJ. Interleukin-5: an eosinophil growth and activation factor. Developments in biological standardization. 1988;69:23-9.

[38] Clutterbuck EJ, Sanderson CJ. Human eosinophil hematopoiesis studied in vitro by means of murine eosinophil differentiation factor (IL5): production of functionally active eosinophils from normal human bone marrow. Blood. 1988 Mar;71(3):646-51.

[39] Lopez AF, Sanderson CJ, Gamble JR, Campbell HD, Young IG, Vadas MA. Recombinant human interleukin 5 is a selective activator of human eosinophil function. J Exp Med. 1988 Jan 1;167(1):219-24.

[40] Wang JM, Rambaldi A, Biondi A, Chen ZG, Sanderson CJ, Mantovani A. Recombinant human interleukin 5 is a selective eosinophil chemoattractant. Eur J Immunol. 1989 Apr;19(4):701-5.

[41] Sanderson CJ. The biological role of interleukin 5. International journal of cell cloning. 1990 Jan;8 Suppl 1:147-53; discussion 53-4.

[42] Lee NA, Lee JJ. Asthma: does IL-5 have a more provocative role? Am J Respir Cell Mol Biol. 1997 May;16(5):497-500.

[43] Till S, Durham S, Dickason R, Huston D, Bungre J, Walker S, et al. IL-13 production by allergen-stimulated $\mathrm{T}$ cells is increased in allergic disease and associated with IL-5 but not IFNgamma expression. Immunology. 1997 May;91(1):53-7.

[44] Zhu Z, Homer RJ, Wang Z, Chen Q, Geba GP, Wang J, et al. Pulmonary expression of interleukin-13 causes inflammation, mucus hypersecretion, subepithelial fibrosis, physiologic abnormalities, and eotaxin production. J Clin Invest. 1999 Mar;103(6):779-88.

[45] Ngoc PL, Gold DR, Tzianabos AO, Weiss ST, Celedon JC. Cytokines, allergy, and asthma. Current opinion in allergy and clinical immunology. 2005 Apr;5(2):161-6.

[46] Kay AB. The role of $\mathrm{T}$ lymphocytes in asthma. Chemical immunology and allergy. 2006;91:59-75.

[47] Barnes PJ. Immunology of asthma and chronic obstructive pulmonary disease. Nature reviews. 2008 Mar;8(3):183-92.

[48] Soroosh P, Doherty TA. Th9 and allergic disease. Immunology. 2009 Aug;127(4):450-8.

[49] Buc M, Dzurilla M, Vrlik M, Bucova M. Immunopathogenesis of bronchial asthma. Archivum immunologiae et therapiae experimentalis. 2009 Sep-Oct;57(5):331-44.

[50] Nath P, Leung SY, Williams AS, Noble A, Xie S, McKenzie AN, et al. Complete inhibition of allergic airway inflammation and remodelling in quadruple IL-4/5/9/13-/- mice. Clin Exp Allergy. 2007 Oct;37(10):1427-35. 
[51] Friend SL, Hosier S, Nelson A, Foxworthe D, Williams DE, Farr A. A thymic stromal cell line supports in vitro development of surface IgM+ B cells and produces a novel growth factor affecting B and T lineage cells. Experimental hematology. 1994 Mar;22(3):321-8.

[52] Liu YJ, Soumelis V, Watanabe N, Ito T, Wang YH, Malefyt Rde W, et al. TSLP: an epithelial cell cytokine that regulates $\mathrm{T}$ cell differentiation by conditioning dendritic cell maturation. Annual review of immunology. 2007;25:193-219.

[53] Rochman Y, Leonard WJ. Thymic stromal lymphopoietin: a new cytokine in asthma. Current opinion in pharmacology. 2008 Jun;8(3):249-54.

[54] Zhou B, Comeau MR, De Smedt T, Liggitt HD, Dahl ME, Lewis DB, et al. Thymic stromal lymphopoietin as a key initiator of allergic airway inflammation in mice. Nature immunology. 2005 Oct;6(10):1047-53.

[55] Jessup HK, Brewer AW, Omori M, Rickel EA, Budelsky AL, Yoon BR, et al. Intradermal administration of thymic stromal lymphopoietin induces a $\mathrm{T}$ cell- and eosinophil-dependent systemic Th2 inflammatory response. J Immunol. 2008 Sep 15;181(6):4311-9.

[56] Zhou B, Headley MB, Aye T, Tocker J, Comeau MR, Ziegler SF. Reversal of thymic stromal lymphopoietin-induced airway inflammation through inhibition of Th2 responses. J Immunol. 2008 Nov 1;181(9):6557-62.

[57] Chow JY, Wong CK, Cheung PF, Lam CW. Intracellular signaling mechanisms regulating the activation of human eosinophils by the novel Th2 cytokine IL-33: implications for allergic inflammation. Cellular \& molecular immunology. Jan;7(1):26-34.

[58] Pushparaj PN, Tay HK, H'Ng S C, Pitman N, Xu D, McKenzie A, et al. The cytokine interleukin-33 mediates anaphylactic shock. Proc Natl Acad Sci U S A. 2009 Jun 16;106(24):9773-8.

[59] Angkasekwinai P, Park H, Wang YH, Wang YH, Chang SH, Corry DB, et al. Interleukin 25 promotes the initiation of proallergic type 2 responses. J Exp Med. 2007 Jul 9;204(7):1509-17. [60] Locksley RM. Asthma and allergic inflammation. Cell. 2010 Mar 19;140(6):777-83.

[61] Tamachi T, Maezawa Y, Ikeda K, Kagami S, Hatano M, Seto Y, et al. IL-25 enhances allergic airway inflammation by amplifying a TH2 cell-dependent pathway in mice. J Allergy Clin Immunol. 2006 Sep;118(3):606-14.

[62] Al-Shami A, Spolski R, Kelly J, Keane-Myers A, Leonard WJ. A role for TSLP in the development of inflammation in an asthma model. J Exp Med. 2005 Sep 19;202(6):829-39.

[63] Kondo Y, Yoshimoto T, Yasuda K, Futatsugi-Yumikura S, Morimoto M, Hayashi N, et al. Administration of IL-33 induces airway hyperresponsiveness and goblet cell hyperplasia in the lungs in the absence of adaptive immune system. International immunology. 2008 Jun;20(6):791800. 
[64] Wakashin H, Hirose K, Maezawa Y, Kagami S, Suto A, Watanabe N, et al. IL-23 and Th17 cells enhance Th2-cell-mediated eosinophilic airway inflammation in mice. Am J Respir Crit Care Med. 2008 Nov 15;178(10):1023-32.

[65] Hellings PW, Kasran A, Liu Z, Vandekerckhove P, Wuyts A, Overbergh L, et al. Interleukin-17 orchestrates the granulocyte influx into airways after allergen inhalation in a mouse model of allergic asthma. Am J Respir Cell Mol Biol. 2003 Jan;28(1):42-50.

[66] Oda N, Canelos PB, Essayan DM, Plunkett BA, Myers AC, Huang SK. Interleukin-17F induces pulmonary neutrophilia and amplifies antigen-induced allergic response. Am J Respir Crit Care Med. 2005 Jan 1;171(1):12-8.

[67] He R, Oyoshi MK, Jin H, Geha RS. Epicutaneous antigen exposure induces a Th17 response that drives airway inflammation after inhalation challenge. Proc Natl Acad Sci U S A. 2007 Oct 2;104(40):15817-22.

[68] He R, Kim HY, Yoon J, Oyoshi MK, MacGinnitie A, Goya S, et al. Exaggerated IL-17 response to epicutaneous sensitization mediates airway inflammation in the absence of IL-4 and IL-13. J Allergy Clin Immunol. 2009 Oct;124(4):761-70 e1.

[69] Wakashin H, Hirose K, Iwamoto I, Nakajima H. Role of IL-23-Th17 cell axis in allergic airway inflammation. International archives of allergy and immunology. 2009;149 Suppl 1:10812.

[70] Lisbonne M, Diem S, de Castro Keller A, Lefort J, Araujo LM, Hachem P, et al. Cutting edge: invariant $\mathrm{V}$ alpha $14 \mathrm{NKT}$ cells are required for allergen-induced airway inflammation and hyperreactivity in an experimental asthma model. J Immunol. 2003 Aug 15;171(4):1637-41.

[71] Shult PA, Graziano FM, Busse WW. Enhanced eosinophil luminol-dependent chemiluminescence in allergic rhinitis. J Allergy Clin Immunol. 1986 May;77(5):702-8.

[72] MacNee W. Oxidants/antioxidants and COPD. Chest. 2000 May;117(5 Suppl 1):303S$17 \mathrm{~S}$.

[73] Rahman I. Regulation of glutathione in inflammation and chronic lung diseases. Mutation research. 2005 Nov 11;579(1-2):58-80.

[74] Barnes PJ. Reactive oxygen species and airway inflammation. Free Radic Biol Med. 1990;9(3):235-43.

[75] Bowler RP, Crapo JD. Oxidative stress in allergic respiratory diseases. J Allergy Clin Immunol. 2002 Sep;110(3):349-56.

[76] Caramori G, Papi A. Oxidants and asthma. Thorax. 2004 Feb;59(2):170-3.

[77] Peden DB, Dailey L. Modulation of mast cell functions by in vitro ozone exposure. The American journal of physiology. 1995 Jun;268(6 Pt 1):L902-10. 
[78] Taylor L, Menconi MJ, Polgar P. The participation of hydroperoxides and oxygen radicals in the control of prostaglandin synthesis. J Biol Chem. 1983 Jun 10;258(11):6855-7.

[79] Kramer K, Rademaker B, Rozendal WH, Timmerman H, Bast A. Influence of lipid peroxidation on beta-adrenoceptors. FEBS Lett. 1986 Mar 17;198(1):80-4.

[80] Schleimer RP, Kato A, Kern R, Kuperman D, Avila PC. Epithelium: at the interface of innate and adaptive immune responses. J Allergy Clin Immunol. 2007 Dec;120(6):1279-84.

[81] Doherty T, Broide D. Cytokines and growth factors in airway remodeling in asthma. Current opinion in immunology. 2007 Dec;19(6):676-80.

[82] Holgate ST. Epithelium dysfunction in asthma. J Allergy Clin Immunol. 2007 Dec;120(6):1233-44; quiz 45-6.

[83] Mauad T, Bel EH, Sterk PJ. Asthma therapy and airway remodeling. J Allergy Clin Immunol. 2007 Nov;120(5):997-1009; quiz 10-1.

[84] Leung DY, Boguniewicz M, Howell MD, Nomura I, Hamid QA. New insights into atopic dermatitis. J Clin Invest. 2004 Mar;113(5):651-7.

[85] Pawankar R, Nonaka M, Yamagishi S, Yagi T. Pathophysiologic mechanisms of chronic rhinosinusitis. Immunology and allergy clinics of North America. 2004 Feb;24(1):75-85.

[86] Elias JA, Zhu Z, Chupp G, Homer RJ. Airway remodeling in asthma. J Clin Invest. 1999 Oct;104(8):1001-6.

[87] Shore SA, Moore PE. Effects of cytokines on contractile and dilator responses of airway smooth muscle. Clin Exp Pharmacol Physiol. 2002 Oct;29(10):859-66.

[88] Komori S, Itagaki M, Unno T, Ohashi H. Caffeine and carbachol act on common Ca2+ stores to release $\mathrm{Ca} 2+$ in guinea-pig ileal smooth muscle. Eur J Pharmacol. 1995 Apr 24;277(23):173-80.

[89] Coulson FR, Fryer AD. Muscarinic acetylcholine receptors and airway diseases. Pharmacol Ther. 2003 Apr;98(1):59-69.

[90] Fryer AD, Jacoby DB. Muscarinic receptors and control of airway smooth muscle. Am J Respir Crit Care Med. 1998 Nov;158(5 Pt 3):S154-60.

[91] Roffel AF, Elzinga CR, Zaagsma J. Muscarinic M3 receptors mediate contraction of human central and peripheral airway smooth muscle. Pulmonary pharmacology. 1990;3(1):47-51.

[92] Eglen RM, Hegde SS, Watson N. Muscarinic receptor subtypes and smooth muscle function. Pharmacological reviews. 1996 Dec;48(4):531-65. 
[93] Gosens R, Zaagsma J, Meurs H, Halayko AJ. Muscarinic receptor signaling in the pathophysiology of asthma and COPD. Respiratory research. 2006;7:73.

[94] Fryer AD, Jacoby DB. Parainfluenza virus infection damages inhibitory M2 muscarinic receptors on pulmonary parasympathetic nerves in the guinea-pig. Br J Pharmacol. 1991 Jan;102(1):267-71.

[95] Sorkness R, Clough JJ, Castleman WL, Lemanske RF, Jr. Virus-induced airway obstruction and parasympathetic hyperresponsiveness in adult rats. Am J Respir Crit Care Med. $1994 \mathrm{Jul} ; 150(1): 28-34$.

[96] Larsen GL, Fame TM, Renz H, Loader JE, Graves J, Hill M, et al. Increased acetylcholine release in tracheas from allergen-exposed IgE-immune mice. The American journal of physiology. 1994 Mar;266(3 Pt 1):L263-70.

[97] Fryer AD, Wills-Karp M. Dysfunction of M2-muscarinic receptors in pulmonary parasympathetic nerves after antigen challenge. J Appl Physiol. 1991 Dec;71(6):2255-61.

[98] Schultheis AH, Bassett DJ, Fryer AD. Ozone-induced airway hyperresponsiveness and loss of neuronal M2 muscarinic receptor function. J Appl Physiol. 1994 Mar;76(3):1088-97.

[99] Hu J, Wang SZ, Forray C, el-Fakahany EE. Complex allosteric modulation of cardiac muscarinic receptors by protamine: potential model for putative endogenous ligands. Molecular pharmacology. 1992 Aug;42(2):311-21.

[100] Blanchet MR, Israel-Assayag E, Cormier Y. Modulation of airway inflammation and resistance in mice by a nicotinic receptor agonist. Eur Respir J. 2005 Jul;26(1):21-7.

[101] Blanchet MR, Langlois A, Israel-Assayag E, Beaulieu MJ, Ferland C, Laviolette M, et al. Modulation of eosinophil activation in vitro by a nicotinic receptor agonist. J Leukoc Biol. 2007 May;81(5):1245-51.

[102] Kalra R, Singh SP, Savage SM, Finch GL, Sopori ML. Effects of cigarette smoke on immune response: chronic exposure to cigarette smoke impairs antigen-mediated signaling in $\mathrm{T}$ cells and depletes IP3-sensitive $\mathrm{Ca}(2+)$ stores. The Journal of pharmacology and experimental therapeutics. 2000 Apr;293(1):166-71.

[103] Savage SM, Donaldson LA, Cherian S, Chilukuri R, White VA, Sopori ML. Effects of cigarette smoke on the immune response. II. Chronic exposure to cigarette smoke inhibits surface immunoglobulin-mediated responses in B cells. Toxicology and applied pharmacology. 1991 Dec;111(3):523-9.

[104] Blanchet MR, Israel-Assayag E, Cormier Y. Inhibitory effect of nicotine on experimental hypersensitivity pneumonitis in vivo and in vitro. Am J Respir Crit Care Med. 2004 Apr 15;169(8):903-9. 
[105] Postma DS, Bleecker ER, Amelung PJ, Holroyd KJ, Xu J, Panhuysen CI, et al. Genetic susceptibility to asthma--bronchial hyperresponsiveness coinherited with a major gene for atopy. The New England journal of medicine. 1995 Oct 5;333(14):894-900.

[106] Ewart SL, Mitzner W, DiSilvestre DA, Meyers DA, Levitt RC. Airway hyperresponsiveness to acetylcholine: segregation analysis and evidence for linkage to murine chromosome 6. Am J Respir Cell Mol Biol. 1996 May;14(5):487-95.

[107] De Sanctis GT, Merchant M, Beier DR, Dredge RD, Grobholz JK, Martin TR, et al. Quantitative locus analysis of airway hyperresponsiveness in $\mathrm{A} / \mathrm{J}$ and $\mathrm{C} 57 \mathrm{BL} / 6 \mathrm{~J}$ mice. Nature genetics. 1995 Oct;11(2):150-4.

[108] Carey VJ, Weiss ST, Tager IB, Leeder SR, Speizer FE. Airways responsiveness, wheeze onset, and recurrent asthma episodes in young adolescents. The East Boston Childhood Respiratory Disease Cohort. Am J Respir Crit Care Med. 1996 Jan;153(1):356-61.

[109] Meurs H, Gosens R, Zaagsma J. Airway hyperresponsiveness in asthma: lessons from in vitro model systems and animal models. Eur Respir J. 2008 Aug;32(2):487-502.

[110] Altounyan RE. Variation of Drug Action on Airway Obstruction in Man. Thorax. 1964 Sep;19:406-15.

[111] Kirby JG, Hargreave FE, Gleich GJ, O'Byrne PM. Bronchoalveolar cell profiles of asthmatic and nonasthmatic subjects. Am Rev Respir Dis. 1987 Aug;136(2):379-83.

[112] Ferguson AC, Wong FW. Bronchial hyperresponsiveness in asthmatic children. Correlation with macrophages and eosinophils in broncholavage fluid. Chest. 1989 Nov;96(5):988-91.

[113] Jeffery PK, Wardlaw AJ, Nelson FC, Collins JV, Kay AB. Bronchial biopsies in asthma. An ultrastructural, quantitative study and correlation with hyperreactivity. Am Rev Respir Dis. 1989 Dec;140(6):1745-53.

[114] Djukanovic R, Roche WR, Wilson JW, Beasley CR, Twentyman OP, Howarth RH, et al. Mucosal inflammation in asthma. Am Rev Respir Dis. 1990 Aug;142(2):434-57.

[115] Wardlaw AJ, Dunnette S, Gleich GJ, Collins JV, Kay AB. Eosinophils and mast cells in bronchoalveolar lavage in subjects with mild asthma. Relationship to bronchial hyperreactivity. Am Rev Respir Dis. 1988 Jan;137(1):62-9.

[116] Hargreave FE, Ryan G, Thomson NC, O'Byrne PM, Latimer K, Juniper EF, et al. Bronchial responsiveness to histamine or methacholine in asthma: measurement and clinical significance. J Allergy Clin Immunol. 1981 Nov;68(5):347-55.

[117] Corry DB, Folkesson HG, Warnock ML, Erle DJ, Matthay MA, Wiener-Kronish JP, et al. Interleukin 4, but not interleukin 5 or eosinophils, is required in a murine model of acute airway hyperreactivity. J Exp Med. 1996 Jan 1;183(1):109-17. 
[118] Bousquet J, Chanez P, Lacoste JY, Barneon G, Ghavanian N, Enander I, et al. Eosinophilic inflammation in asthma. The New England journal of medicine. 1990 Oct $11 ; 323(15): 1033-9$.

[119] Walker C, Virchow JC, Jr., Bruijnzeel PL, Blaser K. T cell subsets and their soluble products regulate eosinophilia in allergic and nonallergic asthma. J Immunol. 1991 Mar $15 ; 146(6): 1829-35$.

[120] Foster PS, Hogan SP, Ramsay AJ, Matthaei KI, Young IG. Interleukin 5 deficiency abolishes eosinophilia, airways hyperreactivity, and lung damage in a mouse asthma model. J Exp Med. 1996 Jan 1;183(1):195-201.

[121] Kobayashi T, Miura T, Haba T, Sato M, Serizawa I, Nagai H, et al. An essential role of mast cells in the development of airway hyperresponsiveness in a murine asthma model. $\mathrm{J}$ Immunol. 2000 Apr 1;164(7):3855-61.

[122] Levitt RC, Mitzner W. Expression of airway hyperreactivity to acetylcholine as a simple autosomal recessive trait in mice. Faseb J. 1988 Jul;2(10):2605-8.

[123] Levitt RC, Mitzner W. Autosomal recessive inheritance of airway hyperreactivity to 5hydroxytryptamine. J Appl Physiol. 1989 Sep;67(3):1125-32.

[124] Mihai C, Iscru DF, Druhan LJ, Elton TS, Agarwal G. Discoidin domain receptor 2 inhibits fibrillogenesis of collagen type 1. Journal of molecular biology. 2006 Sep 1;361(5):86476.

[125] Karp CL, Grupe A, Schadt E, Ewart SL, Keane-Moore M, Cuomo PJ, et al. Identification of complement factor 5 as a susceptibility locus for experimental allergic asthma. Nature immunology. $2000 \mathrm{Sep} ; 1(3): 221-6$.

[126] Neptune ER, Frischmeyer PA, Arking DE, Myers L, Bunton TE, Gayraud B, et al. Dysregulation of TGF-beta activation contributes to pathogenesis in Marfan syndrome. Nature genetics. 2003 Mar;33(3):407-11.

[127] Huh KH, Fuhrer C. Clustering of nicotinic acetylcholine receptors: from the neuromuscular junction to interneuronal synapses. Molecular neurobiology. 2002 Feb;25(1):79112.

[128] Ganguly K, Stoeger T, Wesselkamper SC, Reinhard C, Sartor MA, Medvedovic M, et al. Candidate genes controlling pulmonary function in mice: transcript profiling and predicted protein structure. Physiological genomics. 2007 Nov 14;31(3):410-21.

[129] Krymskaya VP. Targeting the phosphatidylinositol 3-kinase pathway in airway smooth muscle: rationale and promise. BioDrugs. 2007;21(2):85-95. 
[130] Gavett SHaMW-K. Pulmmonary inflammation increases airway reactivity to acetylcholine challenge in genetically hyperresponsiveness, but not hyporesponsive mice. Am Rev Respir Dis 1993;147(A572).

[131] Gueders MM, Paulissen G, Crahay C, Quesada-Calvo F, Hacha J, Van Hove C, et al. Mouse models of asthma: a comparison between C57BL/6 and BALB/c strains regarding bronchial responsiveness, inflammation, and cytokine production. Inflamm Res. 2009 Dec;58(12):845-54.

[132] Wills-Karp M, Ewart SL. The genetics of allergen-induced airway hyperresponsiveness in mice. Am J Respir Crit Care Med. 1997 Oct;156(4 Pt 2):S89-96.

[133] Beasley R, Roche WR, Roberts JA, Holgate ST. Cellular events in the bronchi in mild asthma and after bronchial provocation. Am Rev Respir Dis. 1989 Mar;139(3):806-17.

[134] De Sanctis GT, Daheshia M, Daser A. Genetics of airway hyperresponsiveness. J Allergy Clin Immunol. $2001 \mathrm{Jul} ; 108(1): 11-20$.

[135] Wanner A, Abraham WM, Douglas JS, Drazen JM, Richerson HB, Ram JS. NHLBI Workshop Summary. Models of airway hyperresponsiveness. Am Rev Respir Dis. 1990 Jan;141(1):253-7.

[136] Bates JH, Rincon M, Irvin CG. Animal models of asthma. Am J Physiol Lung Cell Mol Physiol. 2009 Sep;297(3):L401-10.

[137] Herz U, Renz H, Wiedermann U. Animal models of type I allergy using recombinant allergens. Methods (San Diego, Calif. 2004 Mar;32(3):271-80.

[138] Fukunaga J, Abe M, Murai A, Akitake Y, Hosokawa M, Takahashi M. Comparative study to elucidate the mechanism underlying the difference in airway hyperresponsiveness between two mouse strains. International immunopharmacology. 2007 Dec 20;7(14):1852-61.

[139] Shum BO, Rolph MS, Sewell WA. Mechanisms in allergic airway inflammation - lessons from studies in the mouse. Expert reviews in molecular medicine. 2008;10:e15.

[140] Van Hove CL, Maes T, Cataldo DD, Gueders MM, Palmans E, Joos GF, et al. Comparison of acute inflammatory and chronic structural asthma-like responses between C57BL/6 and BALB/c mice. International archives of allergy and immunology. 2009;149(3):195207.

[141] Renz H, Smith HR, Henson JE, Ray BS, Irvin CG, Gelfand EW. Aerosolized antigen exposure without adjuvant causes increased $\operatorname{IgE}$ production and increased airway responsiveness in the mouse. J Allergy Clin Immunol. 1992 Jun;89(6):1127-38.

[142] Kung TT, Stelts D, Zurcher JA, Watnick AS, Jones H, Mauser PJ, et al. Mechanisms of allergic pulmonary eosinophilia in the mouse. J Allergy Clin Immunol. 1994 Dec;94(6 Pt 2):1217-24. 
[143] Eum SY, Haile S, Lefort J, Huerre M, Vargaftig BB. Eosinophil recruitment into the respiratory epithelium following antigenic challenge in hyper- $\operatorname{IgE}$ mice is accompanied by interleukin 5-dependent bronchial hyperresponsiveness. Proc Natl Acad Sci U S A. 1995 Dec 19;92(26):12290-4.

[144] Brusselle G, Kips J, Joos G, Bluethmann H, Pauwels R. Allergen-induced airway inflammation and bronchial responsiveness in wild-type and interleukin-4-deficient mice. Am J Respir Cell Mol Biol. 1995 Mar;12(3):254-9.

[145] Lefort J, Bachelet CM, Leduc D, Vargaftig BB. Effect of antigen provocation of IL-5 transgenic mice on eosinophil mobilization and bronchial hyperresponsiveness. J Allergy Clin Immunol. 1996 Mar;97(3):788-99.

[146] Facincone S, De Siqueira AL, Jancar S, Russo M, Barbuto JA, Mariano M. A novel murine model of late-phase reaction of immediate hypersensitivity. Mediators of inflammation. $1997 ; 6(2): 127-33$.

[147] Russo M, Mariano M, Jancar S. A new murine model of persistent lung eosinophilic inflammation. Memorias do Instituto Oswaldo Cruz. 1997;92 Suppl 2:215-8.

[148] Basso AS, Pinto FA, Russo M, Britto LR, de Sa-Rocha LC, Palermo Neto J. Neural correlates of IgE-mediated food allergy. Journal of neuroimmunology. $2003 \mathrm{Jul} ; 140(1-2): 69-77$.

[149] Costa-Pinto FB, AS.; Britto, LRG.; Malucelli, BE.; Russo, M. Avoidance behavior and neural correlates of allergen exposure in a murine model of asthma. Brain, Behavior and Immunity. 2004.

[150] Mirotti LM, D.; Sá-Rocha, LC.; Costa-Pinto, FA. and Russo, M. Food aversion: A critical balance between allergen-specific IgE levels and taste preference. Brain, Behavior and Immunity. 2009.

[151] Zosky GR, Larcombe AN, White OJ, Burchell JT, Janosi TZ, Hantos Z, et al. Ovalbuminsensitized mice are good models for airway hyperresponsiveness but not acute physiological responses to allergen inhalation. Clin Exp Allergy. 2008 May;38(5):829-38.

[152] James AL, Wenzel S. Clinical relevance of airway remodelling in airway diseases. Eur Respir J. 2007 Jul;30(1):134-55.

[153] Bates JH, Cojocaru A, Haverkamp HC, Rinaldi LM, Irvin CG. The synergistic interactions of allergic lung inflammation and intratracheal cationic protein. Am J Respir Crit Care Med. 2008 Feb 1;177(3):261-8.

[154] Yiamouyiannis CA, Schramm CM, Puddington L, Stengel P, Baradaran-Hosseini E, Wolyniec WW, et al. Shifts in lung lymphocyte profiles correlate with the sequential development of acute allergic and chronic tolerant stages in a murine asthma model. The American journal of pathology. 1999 Jun;154(6):1911-21. 
[155] Kabbur PM, Carson WFt, Guernsey L, Secor ER, Jr., Thrall RS, Schramm CM. Interleukin-10 does not mediate inhalational tolerance in a chronic model of ovalbumin-induced allergic airway disease. Cell Immunol. 2006 Jan;239(1):67-74.

[156] Goplen N, Karim MZ, Liang Q, Gorska MM, Rozario S, Guo L, et al. Combined sensitization of mice to extracts of dust mite, ragweed, and Aspergillus species breaks through tolerance and establishes chronic features of asthma. J Allergy Clin Immunol. 2009 Apr;123(4):925-32 e11.

[157] Wegmann M, Fehrenbach H, Fehrenbach A, Held T, Schramm C, Garn H, et al. Involvement of distal airways in a chronic model of experimental asthma. Clin Exp Allergy. 2005 Oct;35(10):1263-71.

[158] Allen JE, Bischof RJ, Sucie Chang HY, Hirota JA, Hirst SJ, Inman MD, et al. Animal models of airway inflammation and airway smooth muscle remodelling in asthma. Pulmonary pharmacology \& therapeutics. 2009 Oct;22(5):455-65.

[159] Stiffel C, Ibanez OM, Ribeiro OG, Decreusefond C, Mouton D, Siqueira M, et al. Genetics of acute inflammation: inflammatory reactions in inbred lines of mice and in their interline crosses. Exp Clin Immunogenet. 1990;7(4):221-33.

[160] Ibanez OM, Stiffel C, Ribeiro OG, Cabrera WK, Massa S, de Franco M, et al. Genetics of nonspecific immunity: I. Bidirectional selective breeding of lines of mice endowed with maximal or minimal inflammatory responsiveness. Eur J Immunol. 1992 Oct;22(10):2555-63.

[161] Ribeiro OG, Maria DA, Adriouch S, Pechberty S, Cabrera WH, Morisset J, et al. Convergent alteration of granulopoiesis, chemotactic activity, and neutrophil apoptosis during mouse selection for high acute inflammatory response. J Leukoc Biol. 2003 Oct;74(4):497-506.

[162] Araujo LM, Ribeiro OG, Siqueira M, De Franco M, Starobinas N, Massa S, et al. Innate resistance to infection by intracellular bacterial pathogens differs in mice selected for maximal or minimal acute inflammatory response. Eur J Immunol. 1998 Sep;28(9):2913-20.

[163] Biozzi G, Ribeiro OG, Saran A, Araujo ML, Maria DA, De Franco M, et al. Effect of genetic modification of acute inflammatory responsiveness on tumorigenesis in the mouse. Carcinogenesis. 1998 Feb;19(2):337-46.

[164] Bortolatto J, Borducchi E, Rodriguez D, Keller AC, Faquim-Mauro E, Bortoluci KR, et al. Toll-like receptor 4 agonists adsorbed to aluminium hydroxide adjuvant attenuate ovalbuminspecific allergic airway disease: role of MyD88 adaptor molecule and interleukin-12/interferongamma axis. Clin Exp Allergy. 2008 Oct;38(10):1668-79.

[165] Aida Y, Pabst MJ. Removal of endotoxin from protein solutions by phase separation using Triton X-114. J Immunol Methods. 1990 Sep 14;132(2):191-5. 
[166] Russo M, Jancar S, Siqueira ALP, Mello EAG, Mengel J, Ficker SM, et al. Prevention of lung eosinophilic inflammation by oral tolerance. Immunology Letters. 1998;61:15-23.

[167] Mota-Santos TA, Oliveira AF, Gerken SE, Vaz NM. Anaphylaxis with Schistosoma mansoni extracts in normal and infected mice. Revista do Instituto de Medicina Tropical de Sao Paulo. 1985 Jul-Aug;27(4):179-85.

[168] Ovary Z. Passive cutaneous anaphylaxis in the mouse. J Immunol. 1958 Oct;81(4):355-7.

[169] Pick E, Keisari Y. A simple colorimetric method for the measurement of hydrogen peroxide produced by cells in culture. J Immunol Methods. 1980;38(1-2):161-70.

[170] Pick E, Mizel D. Rapid microassays for the measurement of superoxide and hydrogen peroxide production by macrophages in culture using an automatic enzyme immunoassay reader. J Immunol Methods. 1981;46(2):211-26.

[171] Russo M, Teixeira HC, Marcondes MC, Barbuto JA. Superoxide-independent hydrogen peroxide release by activated macrophages. Braz J Med Biol Res. 1989;22(10):1271-3.

[172] Ueno S, Yamada H, Moriyama T, Honda K, Takano Y, Kamiya HO, et al. Measurement of dorsal root ganglion P2X mRNA by SYBR Green fluorescence. Brain research. 2002 Oct;10(2):95-101.

[173] Lekanne Deprez RH, Fijnvandraat AC, Ruijter JM, Moorman AF. Sensitivity and accuracy of quantitative real-time polymerase chain reaction using SYBR green I depends on cDNA synthesis conditions. Analytical biochemistry. 2002 Aug 1;307(1):63-9.

[174] Belmonte KE. Cholinergic pathways in the lungs and anticholinergic therapy for chronic obstructive pulmonary disease. Proc Am Thorac Soc. 2005;2(4):297-304; discussion 11-2.

[175] ten Berge RE, Santing RE, Hamstra JJ, Roffel AF, Zaagsma J. Dysfunction of muscarinic M2 receptors after the early allergic reaction: possible contribution to bronchial hyperresponsiveness in allergic guinea-pigs. Br J Pharmacol. 1995 Feb;114(4):881-7.

[176] Schramm CM, Puddington L, Wu C, Guernsey L, Gharaee-Kermani M, Phan SH, et al. Chronic inhaled ovalbumin exposure induces antigen-dependent but not antigen-specific inhalational tolerance in a murine model of allergic airway disease. Am J Pathol. 2004 Jan;164(1):295-304.

[177] Stengel PW, Gomeza J, Wess J, Cohen ML. M(2) and M(4) receptor knockout mice: muscarinic receptor function in cardiac and smooth muscle in vitro. The Journal of pharmacology and experimental therapeutics. 2000 Mar;292(3):877-85.

[178] Smith N, Johnson FJ. Early- and late-phase bronchoconstriction, airway hyper-reactivity and cell influx into the lungs, after 5'-adenosine monophosphate inhalation: comparison with ovalbumin. Clin Exp Allergy. 2005 Apr;35(4):522-30. 